\title{
UNDERSTANDING SUPPORT - LESSONS FROM A CASE STUDY
}

\author{
Chris Sauer \\ Fujitsu Centre for Managing Information Technology and Organisation \\ Australian Graduate School of Management \\ University of New South Wales \\ Kensington \\ NSW Australia
}

\begin{abstract}
Support from top management and others is agreed to be an important factor in information systems success and failure, but little is written about how it has its effect and how it might be managed to a project's advantage. A recently developed conceptual framework is described. It covers the nature and forms of support, the way suppor affects project outcomes, the bases on which support is provided, and the strategies by which support may be managed. The framework is used to analyse a case study in several stages. At the end of the analysis of each stage, the framework's utility is assessed in terms of its explanatory value and the practical advice it suggests. Areas for furher research are identified.
\end{abstract}

\section{INTRODUCTION}

Top management support has long been recognised as an important factor in information systems success (Ackoff 1960, Ginzberg 1975 cited in Keen \& Scott-Morton 1978, Walton 1989, Jarvenpaa \& Ives 1991). Some writers have recognised the need for support from other sources such as the senior MIS executive (Morgan \& Soden 1973), user managers (Argyris 1971, Lucas, Ginzberg \& Schultz 1990), and the organisation itself (Lucas, Ginzberg and Schultz 1990). For reasons that remain unclear, despite apparently widespread agreement on the importance of support, there has been relatively little research into its role in information systems projects (Ein-Dor \& Segev 1981). Assuming that support does function in ways which are of benefit, it follows that project managers would be advised to consider how to ensure that they receive the support they need. Support, then, needs to be managed just as does the technical effort of building and maintaining a system.

Sauer (1993a) has started the process of constructing a conceptual framework for theorising about support and support management. This will allow us to employ a richer conceptual vocabulary, and, in the longer term, to increase our understanding through a better appreciation of the ways in which support works and how it can be managed to the benefit of a project organisation. As it stands, Sauer's conceptual framework is unrefined. It is a pudding awaiting proof. It is the aim of this paper therefore to test it out on a case study. This will do three things. One, it will allow us to observe its applicability - how useful is it, what does it help explain, what does it not explain? Two, it will raise some interesting research problems. And three, it will suggest some practical morals for project managers.

The next section of this paper summarises Sauer's framework. It is followed by a section which briefly introduces the case study. The case can be readily divided into temporal segments, and so is analysed segment by segment. In the final section the outcomes of the analysis are summarised and conclusions drawn.

\section{THE CONCEPTUAL FRAMEWORK}

Sauer's conceptual framework has four main aspects. The first is constitutive and originative - it says what kind of resource or behaviour constitutes support and indicates its possible sources or origins. The second is functional: it begins the task of showing how support works. The third identifies the bases of support. Then, equipped with knowledge of the way support helps a project and the bases on which it may be provided, it becomes possible to start to identify and analyse the elements of the fourth aspect of the framework, namely those practices and strategies by which support may be managed by a project organisation.

Starting with the first aspect of the framework, what constitutes support? Sauer (1993a) defines it recursively as follows: 
1) the supply of resources, services, and assistance (in controlling contextual contingencies) which contribute to the innovation process conducted by a project organisation, or

\section{activities which generate support}

Anything satisfying the first part of the definition counts as primary support. Thus, the provision of resources (funding), the control of organisational contingencies (fixing), and the technical effort that goes into the innovation process of developing, implementing, operating, and maintaining a system (normal technical work) are all forms of primary support. Sauer also proposes that as system use is usually regarded as critical to success (Lyytinen \& Hirschheim 1987), it also be regarded as a primary form of support. Behaviours which satisfy the second part of the definition count as secondary support. There are three forms of secondary support. Mediation between a project organisation and another source of support counts as power-broking. Activities which promote the social legitimacy of the system or project is another form of support. Commitment is the third.

The framework identifies two types of source of support - internal and external. It is quite apparent that much support will be external to the project organisation - from managers, users and others. The purpose of this distinction is largely to raise awareness of the fact that internal support is a crucial variable too. It should not be overlooked.

How does support work? Plainly, its ultimate value lies in providing necessary inputs to a project. The value of secondary support comes from facilitating this. Support also works by helping the project organisation cope with flaws in the innovation process. This can either be by solving the problem that constitutes the flaw (for example, correcting a bug) or by absorbing the flaw (for example, by 'working around' it). Such support has two possible modes. It can be anticipatory in being ready for activation when required - budgets are anticipatory in this sense. Or, support can be reactive if it is mobilised only in reaction to the appearance of a problem.

What is the basis for support? Why is it provided? Sauer (1992) argued that support was given in exchange for system benefits. Sauer (1993a) views this as too limiting, and suggests that structural and cultural factors are also significant. Where there is an exchange of benefits for support, the benefits may be direct when enjoyed by the supporter or indirect if they are enjoyed by some other party in a network of relationships whom the supporter wishes advantaged. When support is supplied by virtue of some standard organisational arrangement (for example, the organisation's software group maintains system software common to all projects) then it can be said to be structural. When support is supplied because of values shared by a supporter and the project organisation or where certain values are implicit in the system (for example, a believer in organisational decentralisation might support a networked system because it advances the philosophy of decentralisation even though it does not offer her any direct benefits) then it can be said to be culturally based support.

The final component of the framework asks what kinds of support management strategy and practice are available to a project organisation. The support management practices are divided into the structural and non-structural. The structural are those which attempt to institute organisational practices which will assure certain forms of support. They are likely to be the most systematic. The non-structural consist of those activities which attempt to manage support from a single individual and those which are more general in their purpose. Thus, practices such as cooption will be in the former category while attempts to make an organisation's culture more generally supportive will be in the latter category.

Support management strategies will combine various kinds of management practice to achieve a particular emphasis. Four are listed in the current framework. The targetted strategy singles out a small number of important/powerful supporters. The sprayshot approach tries to win support from as many sources as possible. The capture-a-champion strategy involves finding an appropriate stakeholder to champion the project. The decoupling strategy involves trying to reduce the project organisation's dependence on its innovation efforts by finding a sponsor who is less interested in the system's benefits - a central government granting agency might fit the bill (see Kraemer et al 1989 for examples). This taxonomy of strategies helps organise the different ways in which support management practices may be employed.

The framework described in this section is summarised in Table 1. It is valuable both for before-thefact analysis and planning for information systems innovation, and for after-the-fact understanding and explanation. It is therefore both a research tool and an aid for the practitioner. An assessment can be made of what support is needed in terms of the different forms of support, its different 
possible sources, and the modes in which it will need to operate. Analysis of a project organisation's access to support can be achieved via an assessment of the actual bases of support. The map that this analysis provides of the organisational terrain can be used to guide and critically assess the selection of a support management strategy and the practices by which it is to be implemented. The framework will be tested on the case study by using it for explanatory analysis.

What is support?

How does support work?

What are the bases of support?

What types of support management practice are there?

What support management strategies are there?
Primary - funding, fixing, normal technical work, use Secondary - power-broking, promotion of social legitimacy, commitment

Provides necessary inputs

Copes with flaws - overcomes them, absorbs them

Modes - anticipatory, reactive

Exchange of benefits for support, structural arrangements, cultural norms

Structural, non-structural

Targetted, sprayshot, capture-a-champion, decouple system from support

Table 1: Summary of a framework for understanding support and support management

\section{THE CASE STUDY}

The case to be used was researched by the author through interviews and extensive file research mostly between 1985 and 1988 . The intention was largely to explore the problem of information systems failure. One of the insights it threw up was that support had played a major role in the project's life. A more thorough account of the research method can be found in Sauer (1992).

The organisation that sponsored the project was the office of the Australian Public Service Board (referred to here as the Public Service Board). The Public Service Board was directed by a formal board consisting of a chairman and two commissioners (referred to here simply as the Board). Its general responsibility covered all matters to do with employment, industrial relations, training and the like for the Australian Public Service.

The system, called Mandata, was intended to automate the administration of personnel and establishments processes for the whole of the Australian Public Service. The project ran throughout the 1970s before being finally terminated in 1981. What makes it particularly interesting for our present purpose is that support for the project varied considerably over its lifetime. At one stage the project was given a new lease of life by an injection of support while its final demise can be seen to have resulted in part from a chronic haemmorhage of support.

The project's history can usefully be divided into a sequence of temporal segments or stages. The first was an extended initiation stage which involved the gathering of support. The second was an initial development stage that was bedevilled by resource problems. This ended in a review which resulted in a major reorientation of the innovation strategy and a reinjection of support. During the subsequent consolidation stage the innovation strategy began to give way under the strain imposed on it while the project as a whole was subjected to a barrage of criticism. A further review was instituted resulting in a partial abandonment of the project, trimming it back to a minimum viable system, an outcome which left it vulnerable to the environment of public spending cuts. The abbreviated analysis given here necessarily simplifies and finesses much of the project's complexity. However, the full details are not critical to this paper. A far fuller account and analysis is given in Sauer (1992). 


\section{ANALYSIS OF THE CASE}

The analysis of the case tests the conceptual framework as an after-the-fact aid to explanation. It is also expected to identify problems for research and useful lessons or principles for practice. Each stage of the case will be analysed in turn through the following eight questions:

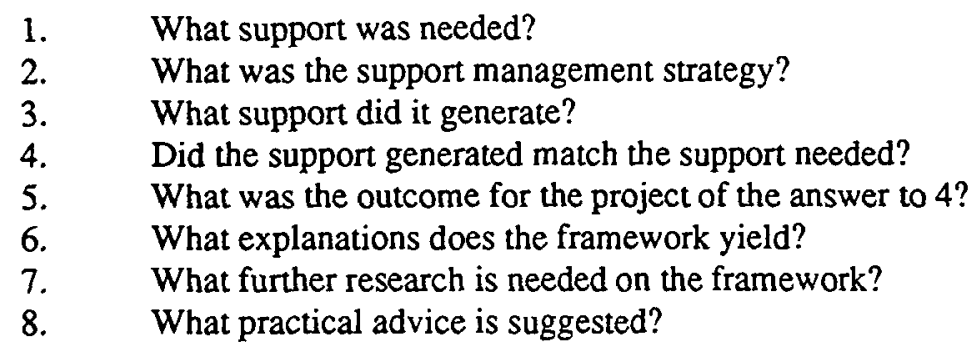

\section{Stage One - Initiation}

The goal of this stage was to obtain a strategic decision to proceed to develop the Mandata project. Formally this was to be a decision by the Cabinet of the Commonwealth Government to fund equipment and system software. To obtain this, a feasibility study had to be launched and funded; its report had to be helped through a lengthy consultation and approval process; a revised proposal had to be funded; and the process of preparing for system development had to be started. The feasibility study report indicated a particular timeframe for this stage which was expected to result in a submission to Cabinet for funding in September 1972. As well as needing support for these essentials of the initiation stage, the project ideally needed a supportive context to be established (Walton 1989) anticipatory of future support needs.

The strategy adopted for winning support in this stage was targetted although it had elements of the sprayshot approach as well. Its central concern was to navigate a path through a sequence of formal decisions. The Board and then various specialist committees had to approve before a proposal could be put to Cabinet. These approvals were substantive decisions which would affect primary support, particularly resourcing. So, the formal decision process imposed a degree of targetting. The strategy was also sprayshot in that some degree of verbal support was required from the permanent heads of Public Service departments and statutory authorities and from the staff associations. This aspect of the strategy was geared to assuring a measure of secondary support for the project, especially social legitimacy, but not to developing primary support.

Initially, the Public Service Board's head of Management Services was a champion for the project. He was able to persuade the Board to support a feasibility study through funding and obtaining secondments. In February 1972, just after completion of this study he retired to be replaced by a less actively supportive manager in approximately the same gatekeeping role. From then on during this stage support had a largely structural basis in that it was obtained by virtue of passage through a formal decision-making process. The ADP Departmental Systems Branch of the Public Service Board received passive support insofar as it was able to persist with the initiation process even though it had no special funding to do so and was required to maintain a full workload at the same time. The formal process of consulting the permanent heads and the staff associations yielded some enhanced legitimacy for the project in the form of a number of statements of support although some responses were qualified or hesitant. For example, one said, 'In our experience, the development of an organisation of the size envisaged would take many years before producing a worthwhile output'. And, one reason given for delays in putting forward the Cabinet submission was the tardiness of the staff associations. However, by mid-1973, the Board was sufficiently convinced that the project would go ahead that it agreed to resource twenty-eight new positions for Mandata in the financial year 1973-74.

The strategy of targetting key decision-makers through the formal decision process ensured that the project received a measure of primary and secondary support sufficient to meet the goal of a favourable Cabinet decision. However, the lack of earmarked funding for initiation between the end of the feasibility study and mid-1973 combined with the loss of the project's champion meant that 
there was no individual or group with sufficient status, access to the Board and time available to enable them to meet the schedule laid down in the feasibility study report. Moreover the formal approach of seeking approval from permanent heads and staff associations yielded only an increase in perceived legitimacy for the project. In not seeking any primary support or even any formal commitment this approach failed to build up a supportive context for future stages. Perhaps most damaging to the project's future was the precise form of the strategic decision. It was a decision by Cabinet to resource Mandata's equipment including some software. It was not an explicit decision to provide either adequate staff or accommodation.

The outcome of this stage was success insofar as the project was approved. However, it was success bought at a price that could not have been easily foreseen or avoided. Because of limited support the project was delayed by nearly eighteen months. This had three undesirable outcomes. First, it set up a situation in which the project's broader context was to be particularly damaging - it was to be caught by funding restrictions as a result of changing national economic and political circumstances. Second, the delay was to be used later as a criticism when the project became subject to external scrutiny. Third, it had not been possible to build up a strongly supportive context. No agreements had been obtained for primary or secondary support beyond the general approvals from permanent heads and staff associations. No special level of commitment had been built up nor had primary support been promised. Thus when the project found itself squeezed it had no reserves of support to call upon.

The lessons of this stage are several. In terms of explaining the project's later difficulties, it is important to understand that limitations to the support available after the feasibility study generated delays which were to subject the project to very damaging contextual circumstances which it lacked the capacity to combat completely. Apparent success in initiation masked what was to become a more deep rooted problem.

In terms of the researcher/theorist's interests a number of problems emerge. First, there is a problem with assigning a strategy type to a set of management practices. In this case, the strategy has been assumed to be largely targetted in that it pursued a formal decision and approval process in which primary support was explicitly asked for from Cabinet alone. The support sought from the other parties appears to have been nominal. However, this may be influenced by the acuity of hindsight. Was it truly a targetted support management strategy? At the time it would have been difficult to estimate what support had in fact been garnered by the initiation process. This constitutes a second, more general problem for work which uses the concept of anticipatory support. How can support be identified in advance of its being called upon? This appears to be a major problem in advancing from the explanatory use of the current conceptual framework to its use predictively to guide practice. It plainly warrants further research.

There are several lessons for the practising manager. The first is that most projects need a variety of forms of support, and apparent success in obtaining that form of support which has most visibility may hide shortfalls elsewhere. Second, it is worth noting that delays can be damaging for more reasons than that benefits are deferred. Uncertainty about the future increases with distance - the further into the future a project is delayed the less certainty there can be about the difficulties likely to arise and therefore about the support that will be needed. A third point related to the second is that it is usually easier to keep established funding than to win new funding. The earlier in a project that support can be won, particularly funding, the better. Consequently, obtaining funding should be a very high priority for most projects. Fourth, as Walton (1989) has proposed, it is important to build up a supportive context. But, that support needs to be balanced. It is not sufficient to have, say, strong legitimacy but no fixers or power-brokers willing and able to help out with unforeseen difficulties. Because some of the effects relating to support developed in this stage only emerged subsequently, further practical morals arising out of initiation will be drawn in the next section.

\section{Stage Two - Initial Development}

The initial development stage concentrated on establishing the social and technical infrastructure for the project and on setting in train the application design work. The former involved issuing a call for tenders for a variety of hardware and software contracts, evaluating the tenders, managing the contracts as they were let, building up a central mainframe facility, designing and installing a continent-wide network, putting together the staff for a project organisation, and designing the application system. The Cabinet proposal had indicated what resource funding would be needed principally, money for the technology, staff, and accommodation. Because of Public Service 
structures the project organisation was dependent on a number of other departments and agencies such as the Australian Government Supply and Tender Board for management of the formalities of the tender process, the National Capital Development Commission (NCDC) for provision of accommodation, the Department of Housing for site works, and the Department of Services and Property for fitting out and maintaining accommodation. Consequently, the project organisation needed them to fix a number of tasks which were outside its own control. As the stage progressed and it became apparent that not all the support needed was forthcoming, there became a requirement for power-broking.

The support management strategy was essentially more of the same from the previous stage. It relied on the Cabinet decision and assumed that that decision implied that support would be forthcoming for all the other needs outlined in the proposal on which it was based. When it became apparent that more support was needed than was provided the main target was the Board itself as both funder and as power-broker. The approach to managing its support was structural inasmuch as it mostly followed formal channels of communication with the Board through the head of the ADP Division. One development in the management of secondary support during this stage was the establishment of a consultative committee of middle managers from the user departments. This had the potential to build support among staff at levels lower than permanent head by encouraging commitment, and promoting legitimacy.

The support actually provided was variable. In some cases, such as the tender process, support appears to have been satisfactory. But, in crucial ways it was less than was needed. The project organisation lacked a champion with both access to and influence over the Board. The head of ADP was slow to open the gate he kept. The Public Service Board and other departments were strongly affected by stringency measures introduced by successive governments in response to difficult economic circumstances nationally. For the whole period the staffing level was well below that desired because of restrictions on establishing and filling new positions. In the financial year of 1975-76, the branch responsible for the system's technical development had a monthly average staff of 32 as against 74 needed according to earlier estimates. In another instance, the NCDC stopped site planning for the central computer because of funding restrictions. In this case, the project was able to summon up sufficient support from the Board and, via it, ministers to overcome the problem, but the result was a facility considerably less than originally specified.

The effects of the limitations to support for this stage were various. The support that was provided was sufficient for some progress to be made but too little to avoid undesirable outcomes. The shortage of staff when combined with contractual imperatives to service the establishment of the technical infrastructure meant that the application design received a lower priority. As a result this aspect of the system development was seriously delayed - by May 1976 the Board was being told that pursuing the then current implementation strategy without a significant injection of resources no implementation date could be promised. Project organisation morale, and hence internal support in the form of technical work and commitment, was affected and the project became vulnerable to a burst of external criticism from the Auditor-General (Auditor-General 1976) and the press. Such criticism became a chronic problem over the following four years and provoked further external scrutiny. The problem with the computer accommodation meant that the computer equipment took longer than expected to accept and suffered continuing performance problems at least in part because of its lack of adequate accommodation.

A particularly interesting outcome for the project was that the build up of all these problems for the project created a political crisis for the Board. Faced with external criticism and no clear implementation date, it had to make a decisive response. It either had to cut its support for the project altogether and abandon it, or it had to revive it with an injection of support. It called in a reviewer who proposed a strategy which would achieve early implementation of some application functions. This strategy was to employ on behalf of a number of client departments the Department of Productivity's existing personnel and establishments system. Initially, the system would be run on spare machine capacity in several other departments' installations. Over time, the system would be converted and ported to the Mandata mainframe. After that the original Mandata system would be implemented. The strategy was agreed, and the reviewer was appointed project director at a level more senior than that of the project's other managers, a position which gave him direct access to the chairman of the Board, and concomitantly greater Board support. So an inadequate level of support ultimately created the conditions by which more support would be generated. But this was only possible because public criticism made abandonment potentially embarrassing and because an acceptable alternative implementation strategy was found. The cost to the project was that the new 
strategy introduced significant new problems because the system adopted was flawed and because porting it to the Mandata computer proved significantly harder technically than was anticipated.

In terms of explaining the project's history an understanding of the problems of support during the initial development stage show how the project reached that critical point at which the Board had to take some radical decision about the project's future. The Board's decision in the face of crisis to increase its support also helps to explain the continuing momentum the project maintained over the next two stages in the following three years. The Board had now made a very visible commitment and would need to justify its investment.

For the researcher, the problem of explaining why the Board decided to continue its support remains outstanding. The best the current framework can offer, deriving from its account of the basis of support, is the suggestion that the Board stood to benefit more from the project's continuation than from its termination. This benefit might have been in terms of embarrassment avoided or political damage from loss of face or a variety of other possible considerations. It might have been subject to a form of escalating commitment (Staw \& Ross 1990). What is clear is that research is needed to refine the concepts which define the bases of support so as to better explain such decisions.

A second problem for the researcher is that the strategies and practices for managing support outlined earlier in the paper do not address the problem encountered by the Mandata project organisation of the withholding of support such as staff resources. How can it be avoided and how should it be dealt with when it does occur? The strategy of decoupling the system from its supporters will only help if alternative support is available. This issue warrants considerable further attention.

For the practitioner, several lessons emerge. Two relate back to the strategic decision taken by Cabinet at the end of the previous stage. First, expressions of support cannot necessarily be relied on to convert to substantive provision of that support. Second, one of the reasons for this is that there is often ambiguity in the interpretation of what is promised. In this case the Cabinet only explicitly supported expenditure on equipment. The project organisation drew the inference that the staff and accommodation and other costs included in the proposal were thereby also sanctioned. However, this left potential supporters such as the NCDC room for manoeuvre when economic restrictions were imposed. They had neither promised support nor had the Cabinet explicitly instructed that they should give it. A further related lesson is that support is contingent in that had economic circumstances not changed it is quite likely that the staffing and accommodation resources would have been readily provided.

Two further lessons concern the project organisation's ability to manage support. In automating personnel and establishments record keeping Mandata did not constitute a strategic application for any major stakeholder. It lacked leverage. It also lacked ready access to its most obvious source of support, the Board, because its structural route was through a gatekeeper and because it had no champion. Either of these conditions is likely to be enough to prevent a project organisation maintaining its support in adverse circumstances.

The case of the Board's intervention to secure accommodation for the central mainframe when it was endangered by the NCDC's decision to stop site planning is also instructive. That the project organisation did not get what it really wanted serves to indicate that even where reactive support is provided, it may not be sufficient to retrieve the situation fully. The outcome was consequential problems with the both the equipment and its accommodation.

Finally, a practitioner faced with difficulties in managing support, in particular in obtaining promised or expected support, would do well to dwell on the Mandata experience. Each effort to obtain the desired support is costly to the project organisation. It is impossible to know and very hard to estimate what the outcome will be. Will this effort be successful and yield all the desired support or will it merely lead to another effort because it only yields some proportion of what is needed? This uncertainty can be both debilitating and inhibiting to the formulation of some more rational project strategy based on the limited support actually available.

\section{Stage Three - Reorientation}

The reorientation stage instituted a major change in project strategy in order to achieve earlier implementation. For this it needed considerable support. All forms of primary support were needed. It needed funding to get the project organisation to a size where it could implement, operate and maintain a large application system for a number of departments at once. In adopting its new strategy the project placed itself in the hands of the technical staff of the departments whose system it was implementing and whose computers it was using. Being knowledgeable about the system the 
Department of Productivity's technical staff would be crucial fixers of applications problems. Naturally, internal technical work was required to get this strategy off the ground and to subsequently convert the system to run on the Mandata mainframe. With the new strategy emphasising implementation it also became important that users actually use the system. Also all forms of secondary support were needed. Power-broking was necessary to help manage the critical external environment. The promotion of social legitimacy was required to combat criticism. And commitment was needed because the new strategy, having been formulated quickly, was a calculated risk and inevitably would require continuing support to help solve unimagined difficulties.

The new implementation strategy was in part a support management strategy as well. It targetted three critical groups - the project organisation itself, the Board, and users. By bringing forward implementation of an application, it disarmed the concerns of some staff internal to the project and enhanced their morale. It gave the Board a response to the critics and a chance to avoid further damage to its prestige. It aimed to win the support of users by involving them further, most obviously by providing them with a service which would then serve as leverage for future support.

The project was mostly well supported during this stage. The new director was positioned to command more Board support in the form of funding for more staff and power-broking to acquire new office accommodation. The strategy itself served to win back support from disaffected members of the project organisation. Users were mobilised to contribute resources to facilitate the implementation and so increase the probability of active use. At the same time, though, the project continued to be under resourced. It requested loans of computer systems officers from departments, but all refused. The departments providing technical support for the operational system generally contributed what was needed but their willingness to do so without compensation declined over time. Mandata's public stock rose with the new momentum although not sufficiently to avoid some continuing criticism.

The support provided was only slightly less than was needed. In consequence the new strategy got under way with few hindrances. This met many of the political difficulties facing the Board. The cost lay in the risk associated with the new strategy.

The lessons of this stage relate mostly to the possibility of the transformation of a troubled project given sufficient support. This is not a matter which receives much attention in the traditional systems development literature. In view of the number of projects that run into trouble it would seem that the support perspective has something distinctive to offer. In this case it took a political crisis to create the conditions in which such a transformation could occur. How necessary this is is unclear although there is some evidence in other literatures that a crisis is an important precondition of radical change (Pettigrew 1985 Child, Ganter \& Kieser 1987). Although the point has not really emerged in the above analysis, another lesson, if more minor, is that the improved image of the Mandata project indicates that some problems and criticisms can be dispersed by a radical shift in strategy. By eradicating the original basis for criticism, the critic is disarmed.

The other major lesson is that although a radical shift in strategy can be beneficial in terms of its immediate effect on support it needs to be recognised that it is unlikely that the new strategy will be as well thought out and its implications as well understood as if it had been the strategy followed since the project's inception. When the decision to reorient is taken under political pressure this danger will be acute.

Finally, a lesson which is apparent in the next stage, too, is that structural positioning is important in managing support. The improved access of the new director undoubtedly benefited the project in assuring improved support from the top. And this in turn benefited legitimacy. with consequential effects for commitment.

\section{Stage Four - Consolidation}

Where the third stage introduced a major change of direction, the consolidation stage aimed at bringing the new implementation strategy to fruition. This involved implementation of the interim system in many user departments and development of a new system along the lines originally envisaged. The management of this stage was undertaken by a new project director.

Initially, the main needs for support were funding and technical work to maintain project momentum; fixing by application staff in departments to get their personnel and establishments records into a condition from which they could be computerised as well as continued fixing by the departments providing system support; and, when implementation was achieved in a department, the system needed to be used. Secondary support was also necessary to promote the provision of the primary 
support - legitimacy to combat criticisms from external sources and departmental users, commitment to generate other forms of support, and power-broking to facilitate its provision where not immediately available. A high level of anticipatory support was needed as the uncertainty arising from the implementation strategy and contextual contingencies was high. As the stage progressed, new problems emerged requiring previously unanticipated support.

The support management strategy continued to target key supporters but also included a greater element of the sprayshot approach. The new director was known for maintaining a wide network of contacts throughout the Public Service. At the same level as his predecessor, he was able to maintain good links with the Board through regular formal and informal reporting sessions. $\mathrm{He}$ also emphasised the continuing involvement of users at the management and supervisory levels in two committees which met regularly. When faced with increased external scrutiny from the AuditorGeneral and then the Public Accounts Committee, he called upon supporters to defend the project.

The support provided by the Board, the project's own staff, and by user departments was sufficient to sustain the technical effort involved in implementing the system in twelve departments and to the new development of several sub-systems. Conversion to the Mandata computer ran only a few months late. But, there was not enough slack to allow the project organisation to compensate for the flaws which persisted in both the converted system and in some newly developed sub-systems. These same flaws caused user departments to continue to run clerical systems in parallel thereby undermining much of the legitimacy their use of the system promoted. Under critical attack from the Auditor-General (Auditor-General 1976, 1977, 1978, 1979, 1980), the Public Accounts Committee (JCPA 1979), the press, and the staff associations, the Board gave considerable support in an effort to counter the damage the criticisms caused to legitimacy and commitment. However, even this support proved sufficient only to effect a rearguard action and to moderate the worst of the criticisms. Overall, then, the support given to the project organisation was sufficient to sustain continuing development, operation and maintenance, but it was not sufficient to permit eradication of all flaws and shortcomings nor to generate the supportive context necessary to the development of the original system.

The outcome was a situation in which a seriously flawed system was operational but for which there continued to be a clerical alternative. Departments were, at most, only partially dependent on the system. At the same time the project's legitimacy had been seriously damaged by the AuditorGeneral's annual critique, by a severely critical report by the Public Accounts Committee and by sensational press coverage. The project organisation's ability to leverage support for further development to replace the flawed system was therefore seriously impaired despite the fact that the Public Accounts Committee ultimately supported continued development of the project. The final recognition that key flaws could not be rectified without redeveloping the core system and that there was not support for that redevelopment forced upon the project organisation a scaling back of ambitions while at the same time leaving it wide open to termination as part of governmental cost cutting.

Analysis of the support management strategy and the adequacy of the actual support received helps us to see how Mandata was able to continue as a functional project into the late 1970 s but at the same time how its prospect of surviving long into the 1980 s was rendered poor. The crucial contrast here is between the support needed and available to pursue a continuing implementation strategy and that needed and available to rectify flaws in the strategy. The project organisation was unable to build up a level of support sufficient for future needs. No doubt part of the reason for this was its inability to satisfactorily manage perceptions of its performance. The critics were too vocal.

Thus one way in which the conceptual framework might be usefully extended would be to develop an account of the factors which influence what support can be built up. How important is performance? How important are criticisms? Then, the research might be extended to consider practices which help combat negative influences on support.

Finally, the chief lesson of the consolidation stage for the practising manager is that however well support may be managed in the present, negative perceptions of performance can undermine the support needed for future efforts particularly if they involve any shift in type of activity. Where performance is to be evaluated in terms of the quality of an implementation which has not yet been completed it will not be known until that implementation is complete how support will be affected. In other words implementation may cause a significant reduction in the support from a currently satisfactory level to one which constrains future options. A subsidiary moral is that criticism is important. It can be seriously detrimental even if there is considerable support to counteract it. 


\section{Stage Five - Scale Back And Termination}

In the first half of 1980 the project organisation, the Auditor-General's staff and the departmental users independently of each other reached the conclusion that the existing core system was inadequate as a basis for future extension. There was very little support for developing a replacement even within the project. A consensus emerged that the project's ambitions should be scaled back to whatever minimum was necessary to achieve operational viability.

In the short term, the project continued to need much the same level of resources because there continued to be a large amount of work. The project continued to rely upon users to help it fix flaws in the system. Public criticisms and their fall-out continued to command attention and responses. So considerable support was still needed despite the decision to scale back.

The strategy for maintaining support, though still involving attention to the Board and users, now centred on satisfying them through providing a valued service. This continued to yield the level of resources needed for the new scaled back project. Moreover, users were now sufficiently supportive that they could be coordinated into a joint rebuttal of the Auditor-General's most stinging criticisms in his April 1980 report (Auditor-General 1980). Whether or not as a result of this or as a result of continuing lobbying by the Board, a few months later the Auditor-General agreed to take the pressure off the project. So, once again support was adequate for the project's continuing existence. Crucially, though, in finally abandoning the original project objectives the project organisation could no longer offer future benefits that would justify the total investment that had been made in the project. In this it forfeited the basis for its funding. Thus, when funding became threatened by a governmental cost cutting exercise it had no adequate ground on which to defend itself. Indeed, for its chief sponsor, the Board, termination through the need for cuts was probably welcome. It gave a face saving excuse for relieving the Board of a public embarrassment.

In an earlier section it was concluded that the conceptual framework exemplified in this paper might be usefully enhanced by an elaboration of its account of the bases of support. The suggestion that the Board might have supported the project because it could see no politically acceptable way out underlines this. Support need not be based solely on benefits, structure and culture, but also may be based on the avoidance of the disadvantages incurred by not giving support.

The experience of the termination of Mandata also highlights the contingency of support. Had economic conditions been less straitened the cost cutting exercise might never have happened and the strategy of bedding down a minimum viable system might have been successful. Clearly, context is an important source of influence on support.

Analysis shows that the project was terminated because it no longer had a basis for justifying its funding. The obvious lesson for practitioners is that the loss of a financial rationale may render funding vulnerable although the decoupling strategy for managing support seeks to avoid this.

The other lesson is that partial abandonment (as in the decision to scale back Mandata) is a realistic option when a project is in trouble (see Sauer 1993b). In this case, it did not manage to assure the long term survival of the project. However, it did permit its continuance long enough for a face saving resolution to emerge. This is not a negligible consideration. For members of a project organisation concemed about the effects on their careers as a result of association with a failed project or for supporters who have had long association with the project such an outcome may be highly desirable.

\section{CONCLUSION}

Testing the conceptual framework on a case study was advertised as having three benefits - it would demonstrate the framework's value in offering explanatory insights; it would highlight ways in which the framework could be improved; and it would offer useful lessons for the practising information systems project manager. At the end of each section analysing a stage of the case study conclusions have been drawn. It is now appropriate to consider what more general conclusions can be reached. First, the framework has demonstrated that it can help explain the ups and downs of the Mandata project, in particular why it was able to continue when it encountered difficulties and why ultimately it could not survive in its scaled down form. Indeed, in view of the fact that the project and system were in better shape in 1981 than at the time when it was decided to scale back, it is only through analysing the project's support that its termination can be understood. This is not to say that 
analysing support explains all facets of a project's history. The technical development of the innovation is still important. But, the support analysis perspective sheds light where otherwise matters might remain obscure.

Second, the adequacy of the framework has been tested. All aspects of it have been used. One facet which has not received much attention but which could usefully be explored is the linkages among different forms of support. For example, visible primary support is likely to have a positive effect on perceived legitimacy. Perceived legitimacy is likely to have a positive effect on other forms of support. However, perceptions of supporters could influence these effects. Stakeholder X might have a negative opinion of $Y$ and view $Y$ 's support of a project as a reason for not supporting it. So, to understand the likely influence of support we need a more sophisticated understanding of how forms of support interact and how they may be modified.

This leads to further consideration of the bases of support. A better account of why supporters support a project is needed. As noted earlier, it is more complicated than a rational exchange. In addition to structural and cultural bases we have discovered that support may be given because the alternative looks less attractive. The contingency of support has been noted. Even where a potential supporter sees benefits from giving support there may be external factors which discourage or prevent this from being converted into something usable. The framework has nothing to say about contextual influences on support. This needs to be rectified.

Another aspect that receives no attention in the framework is the matter of the balance of different forms of support. Not only does the level of support vary over time, the levels of the forms of support may differ at one time. It may therefore be useful to think in terms of a profile of support. To do this, and to make practical use of the matching of needs for support and available support it will be necessary to attempt some kind of operationalisation of levels of support.

Third, various lessons have been drawn for the practitioner. The central lesson is that support is crucial to projects. It is necessary in different amounts of its various forms at every stage. It is a major reason that projects are able to continue even under adverse conditions. As the reorientation of Mandata demonstrates, it can be used to radically change the direction of a project, perhaps saving it from termination and loss of all potential benefits. The moral for the practitioner is that it is important to attempt to manage support in order to smooth a project's path and enhance its prospects of continuing when faced with adverse conditions. To manage only the technical development of a system and to leave support to chance is to manage only half of an information systems project.

At present, then, although the conceptual framework presented and tested here has been shown to be valuable in a number of ways, it has also been shown to be limited. Future empirical research on the ways in which support works in projects and on the ways by which it is managed will contribute to a more sophisticated conceptual framework. An improved framework will provide a basis for a theory of support from which soundly based advice can be formulated. Until then researchers and practitioners have at least a partial framework by which to think about support, and that is a significant advance.

\section{REFERENCES}

Ackoff, R.L. (1960) Unsuccessful case studies and why, Operations Research, 8, 4, March-April, 259-263.

Argyris, C. (1971) Management information systems: the challenge to rationality and emotionality, Management Science, 17, 6, Feb, B-275-292.

Auditor-General (1976) Report of the Auditor-General for the Year Ended 30 June 1976, AGPS, Canberra.

Auditor-General (1977) Report of the Auditor-General for the Year Ended 30 June 1977, AGPS, Canberra.

Auditor-General (1978) Report of the Auditor-General for the Year Ended 30 June 1978, AGPS, Canberra.

Auditor-General (1979) Report of the Auditor-General for the Year Ended 30 June 1979, AGPS, Canberra.

Auditor-General (1980) Report of the Auditor-General, AGPS, Canberra, April 1980. 
Child, J., Ganter, H-D. \& Kieser, A. (1987) Technological innovation and organizational conservatism, in Pennings, J.M. \& Buitendam, A. (eds), New Technology as Organizational Innovation: The Development and Diffusion of Microelectronics, Ballinger, Cambridge, Ma..

Ein-Dor, P. \& Segev, E. (1981) A Paradigm for Management Information Systems, Praeger, New York.

Ginzberg, M.J. (1975) A process approach to management science implementation, PhD dissertation, MIT.

Jarvenpaa, S.L. \& Ives, B. (1991) Executive involvement and participation in the management of information technology, MIS Quarterly, June, 205-227.

JCPA (1979) 175th Report of the Joint Committee of Public Accounts of the Parliament of the Commonwealth of Australia: Use of ADP in the Commonwealth Public Sector - The

MANDATA Project, Australian Government Publishing Service, Canberra, September.

Keen, P.G.W. \& Scott Morton, M.S. (1978) Decision Support Systems: an Organizational Perspective, Addison-Wesley, Philippines.

Kraemer, K.L., King, J.L., Dunkle, D.E. \& Lane, J.P. (1989) Managing Information Systems: Change and Control in Organizational Computing, Jossey-Bass, San Francisco.

Lucas, H.C. Jr, Ginzberg, M.J. \& Schultz, R.L. (1990), Information Systems Implementation: Testing a Structural Model, Ablex Publishing Corp, Norwood, New Jersey.

Lyytinen, K. \& Hirschheim, R. (1987) Information systems failures: a survey and classification of the empirical literature, Oxford Surveys in Information Technology, Vol 4, 257-309.

Morgan, H.L. \& Soden, J.V. (1973) Understanding MIS failures, Data Base, 5, Winter.

Pettigrew, A.M. (1985) Examining change in the long-term context of culture and politics, in Pennings, J.M. and Associates, Organizational Strategy and Change, Jossey-Bass, San Francisco, 269-318.

Sauer, C. (1992) Information Systems Failure: The Problem of Managing Support for a Flawed Innovation Process, PhD thesis, University of Western Australia, Perth, WA.

Sauer, C. (1993a) Support and support management in information systems projects: building a conceptual framework, mimeo.

Sauer, C. (1993b) Partial abandonment as a strategy for avoiding failure, in Avison D.E., deGross, J. \& Kendall, J. (eds) Information Systems Development: Human, Social and Organizational Aspects, Proceedings of IFIP WG8.2 Working Conference, Noordwijkerhout, 17-19 May 1993, Elsevier (North Holland).

Staw, B.M., \& Ross, J. (1990) Behavior in escalation situations: antecedents, prototypes, and solutions, in Staw and Cummings, L.L. (eds) The Evolution and Adaptation of Organizations, JAI Press, Greenwich, Conn, 1990,191-230.

Walion, R.E., (1989) Up and Running: Integrating Information Technology and the Organization, Harvard Business School Press, Boston, Massachusetts. 